\title{
Modelling of damage development and failure in notched bar multiaxial creep tests
}

\author{
M. Yatomi, N. P. O'Dowd, K. M. Nikbin \\ Department of Mechanical Engineering, Imperial College of Science, Technology and \\ Medicine, London SW7 2BX, England
}

\begin{abstract}
Finite element predictions of creep rupture in notched specimens are presented in this work. A damage mechanics model linked to the creep strain rate and stress triaxiality has been adopted in order to predict creep life under multiaxial stress conditions and the predicted creep failure strain and time to rupture have been compared with experimental data for a C-Mn steel tested at $360{ }^{\circ} \mathrm{C}$. Finite element analyses have been conducted for primary-secondary (PS) and primary-secondary-tertiary (PST) creep laws. As expected a PST analysis gives more conservative predictions than a PS analysis. An additional term was included in the model to allow for an increase in hydrostatic strain due to creep damage. Under certain conditions incorporating this 'elastic damage' term can lead to an increase in the predicted failure time (i.e. it is less conservative). A further enhancement to the model was to include the effect of crack growth through the use of a nodal release technique. It was found that the predictions obtained using the nodal release technique were very similar to those from the PST creep model with elastic damage. Furthermore, it was found that the inclusion of plasticity (i.e. rate independent inelastic strains) may decrease the conservatism in the prediction (an increase in the predicted life). The sensitivity of the results to the value of the uniaxial creep failure strain and the stress triaxiality model used in the definition of damage were examined and it was found that both these factors strongly affected the predicted rupture time. Mesh size effects were also examined and the finite element predictions were seen to be quite mesh sensitive with a finer mesh giving more conservative predictions.
\end{abstract}

Keywords: Creep rupture, Damage mechanics, finite element analysis, notched bar, multiaxiality 


$\begin{array}{ll}\text { Nomenclature } & \\ A, n & \text { material constants in secondary creep law } \\ C_{1}, C_{2}, n_{1} & \text { material constants in primary creep law } \\ E, E_{0} & \text { Young's modulus of material and of undamaged material } \\ m & \text { material constant in tertiary creep law } \\ S & \text { elastic compliance tensor } \\ \mathrm{t}_{\mathrm{rmin}}, \mathrm{t}_{\mathrm{rmax}} & \text { predicted minimum and maximum creep rupture time } \\ \varepsilon, \dot{\varepsilon} & \text { strain, strain rate } \\ \varepsilon^{c}, \dot{\varepsilon}^{c}, \varepsilon^{c}{ }_{e q} & \text { creep strain, creep strain rate, equivalent creep strain } \\ \dot{\varepsilon}_{\omega}^{c} & \text { creep strain rate modified due to damage accumulation } \\ \varepsilon_{f} & \text { uniaxial failure strain } \\ \varepsilon_{f}^{*} & \text { multiaxial failure strain } \\ \varepsilon^{e}, \dot{\varepsilon}^{e} & \text { elastic strain, elastic strain rate } \\ \dot{\varepsilon}^{p} & \text { plastic strain rate } \\ \sigma, \dot{\sigma} & \text { stress, stress rate } \\ \sigma_{0.2}, \sigma_{\mathrm{UTs}} & \text { yield strength, ultimate tensile strength } \\ \sigma_{e}, \sigma_{m} & \text { effective (Mises) stress, hydrostatic stress } \\ \omega, \dot{\omega}, \omega_{\text {max }} & \text { damage, damage rate, maximum value of damage } \\ & \end{array}$

\section{Introduction}

Most components operating at elevated temperature are subjected to multiaxial stress conditions due to mechanical and thermal loadings. Under these conditions components often suffer creep damage resulting from the formation, growth and coalescence of microcavities and creep rupture is an important failure mode for such components [1]. There is therefore a need for engineers to be able to predict accurately the extent of creep damage and the time to rupture under multiaxial stress conditions. In addition the importance of the multiaxial creep rupture stress criterion of a given material in design analysis has been recognized and highlighted in [2] and [3]. A convenient and effective method of introducing a state of multiaxial stress in laboratory tests is by subjecting circumferentially notched bars to an axial tensile load [4]. By altering the notch profile a wide range of stress states can be generated allowing the effect of multiaxiality on material behaviour to be studied [5] in a systematic fashion.

In this paper, a damage mechanics model, following that introduced by Kachanov [6] and Robotnov [7], based on the effective creep strain rate, has been adopted. The model will be used to predict creep rupture life in notched specimens under constant load using finite element (FE) techniques. The analyses have been conducted using primary-secondary (PS) and primary-secondary-tertiary (PST) creep material laws. In the former the damage parameter is uncoupled from the material response; in the latter the evolution of damage accelerates the creep strain rate in the manner proposed in [6], [7]. The use of continuum damage mechanics models for creep within a finite element framework has been studied by a number of authors, e.g. Hyde et al. [8], Harlow et al. [9], Bodnar et al. [10], Bettinson [11]. Hayhurst et al. 
[12] extended the approach used in the earlier works by allowing the removal of elements when the damage reaches a critical value. This model was further improved by Perrin and Hayhurst [13] and Bhattacharya and Ellingwood [14] who incorporated the effect of elastic damage in the response (this will be discussed further in section 2 below).

In the current work, continuum damage mechanics models have been applied to the study of a carbon manganese (C-Mn) steel under multiaxial loading. This material is widely used in tube and pipe in power station boilers. The models are extended to allow for crack growth in the vicinity of a relatively sharp notch and comparisons made between the different approaches. A thorough sensitivity study to the effect of problem parameters and finite element mesh size has also been conducted. The predictions from the finite element models are compared with experimental data for the material.

\section{Material model}

The total strain rate at any point within the specimen may be considered to be the sum of elastic $\left(\dot{\varepsilon}^{e}\right)$, plastic $\left(\dot{\varepsilon}^{p}\right)$ and creep $\left(\dot{\varepsilon}^{c}\right)$ strain rate contributions:

$$
\dot{\varepsilon}=\dot{\varepsilon}^{e}+\dot{\varepsilon}^{p}+\dot{\varepsilon}^{c}
$$

Here the inelastic strain is divided into a rate independent 'plastic' term and a rate dependent 'creep' term. The calculation of each of these contributions is detailed in the following sections.

\subsection{Elastic-plastic strain rates}

The elastic response is assumed to be rate independent and the elastic strain rate is given by the usual isotropic expression,

$$
\dot{\varepsilon}^{\mathrm{e}}=S \dot{\sigma}
$$

where $\boldsymbol{S}$ is the elastic compliance and $\dot{\sigma}$ is the stress rate. The isotropic elastic constants for the C-Mn steel are given in Table 1. The plastic response is assumed to be governed by a Mises flow rule with isotropic strain hardening and was obtained by fitting to uniaxial tensile test data at $360^{\circ} \mathrm{C}$ [15]. The material yield strength is 240 $\mathrm{MPa}$ and the post-yield strain hardening response is treated as piece-wise linear up to the UTS (see Table 1) beyond which no strain hardening occurs. For an elastic-creep analysis or during unloading the plastic strain rate is zero.

\subsection{Primary, secondary creep rate}

Creep deformation is generally represented as being composed of three stagesprimary, secondary and tertiary creep [16]. The primary creep strain is often given in a power-law form as [17]

$$
\varepsilon_{p}=C_{1} \sigma^{n_{1}} t^{C_{2}}
$$

where $C_{1}, C_{2}$ and $n_{1}$ are material constants obtained from uniaxial creep data. From Eq. (3) the primary creep strain rates for strain hardening equations of state can be therefore written as, [17],

$$
\dot{\varepsilon}_{p}=C_{2}\left(C_{1} \sigma^{n_{1}}\right) \frac{1}{C_{2}} \varepsilon^{\frac{c_{2}-1}{c_{2}}}
$$


The secondary creep strain rate for many materials can be represented via a power law, [18], i.e.,

$$
\dot{\varepsilon}_{s}=A \sigma^{n}
$$

where $A$ and $n$ are material constants obtained from uniaxial creep data. Table 2 shows the material constants in the primary and secondary creep law for C-Mn steel at $360^{\circ} \mathrm{C}$. Note that in this work creep deformation is assumed to be incompressible and $\sigma$ and $\dot{\varepsilon}$ in Eqs. (3)-(5) are the equivalent (Mises) stress and equivalent creep strain rate, respectively.

\subsection{Damage accumulation and tertiary creep}

To incorporate the effects of tertiary creep, a creep damage approach is used following the work of [6] and [7]. A damage parameter $(\omega)$ is established such that $0 \leq \omega \leq 1$ and failure occurs when $\omega=1$. In this work $\omega$ is defined as the ratio of the creep strain to the creep ductility and the rate of accumulation of damage is given via,

$$
\dot{\omega}=\frac{\dot{\varepsilon}^{c}}{\varepsilon_{f}^{*}}
$$

where $\varepsilon_{f}^{*}$ is the (multiaxial) creep ductility to be defined more precisely later. The total damage at any time, $t$, is then the integral of the damage rate up to that time:

$$
\omega=\int_{0}^{t} \dot{\omega} d t
$$

In this work the use of both coupled and uncoupled damage approaches are examined. In the former, known hereafter as the primary-secondary (PS) creep model, the damage evolution follows Eq. (7) but has no effect on the deformation and $\omega$ is simply a damage indicator. In the coupled model, known hereafter as the primarysecondary-tertiary (PST) creep model, following [6], [7], the creep strain rate increases with $\omega$ according to:

$$
\dot{\varepsilon}_{\omega}^{\mathrm{c}}=\frac{\dot{\varepsilon}^{\mathrm{c}}}{(1-\omega)^{m}}
$$

where $\dot{\varepsilon}_{\omega}^{\mathrm{c}}$ is the equivalent creep strain rate allowing for the accumulation of damage and $m$ is a material constant. The incorporation of this damage parameter leads to rapid increase in the creep strain rate as $\omega \rightarrow 1$.

In the above formulation which has been adopted in [8]-[12] damage only affects the creep strain and elastic and plastic strains are unaffected. However, since creep flow is incompressible this implies that even as $\omega \rightarrow 1$, the hydrostatic strain component remains finite and therefore the hydrostatic stresses may not reduce to zero when $\omega \rightarrow 1$ [13]. In [19], a modified creep potential was introduced which resulted in a dilatational creep term when damage is non-zero, (i.e. $\dot{\varepsilon}_{k k}{ }^{c} \neq 0$, when $\omega>0$ ) and thus all strain rates become infinite when $\omega \rightarrow 1$. An alternative approach was adopted in [13] whereby the creep response remains incompressible, but damage is incorporated into the elastic term by allowing the Youngs modulus, $E$, to reduce to zero as $\omega \rightarrow 1$, i.e., [13], [14] 


$$
E=E_{0}(1-\omega)
$$

where $E_{0}$ is the modulus of elasticity for an undamaged material. This ensures that all stress components reduce to zero as $\omega \rightarrow 1$. This latter approach is adopted here and the effect of introducing the additional damage term through the elastic material behaviour is examined. This model will be referred to hereafter as the PSTE model.

\subsection{State of stress effect}

It is well known that failure strain depends on stress state, with an increase in hydrostatic stress leading to an apparent reduction in the ductility. A number of models (e.g. [20]-[24]) have been proposed to account for this dependence and are generally based on the growth of a void in a deforming medium. These models show that the void growth rate is a function of the ratio between the hydrostatic stress $\left(\sigma_{m}\right)$ and the equivalent stress $\left(\sigma_{e}\right)$. This ratio, $\left(\sigma_{m} / \sigma_{e}\right)$, is often known as the triaxiality. Two models which incorporate the effect of triaxiality on the failure strain are considered here. One is based on the Rice and Tracey void growth model [20] (see appendix which reproduces a result from [11]) and the other is the model due to Cocks and Ashby [21]. These models are represented, respectively, by Eqs. (10) and (11),

$$
\begin{aligned}
& \frac{\varepsilon_{f}^{*}}{\varepsilon_{f}}=\frac{0.521}{\sinh \left(\frac{3 \sigma_{m}}{2 \sigma_{e}}\right)} \\
& \frac{\varepsilon_{f}^{*}}{\varepsilon_{f}}=\sinh \left[\frac{2}{3}\left(\frac{n-1 / 2}{n+1 / 2}\right)\right] / \sinh \left[2\left(\frac{n-1 / 2}{n+1 / 2}\right) \frac{\sigma_{m}}{\sigma_{e}}\right]
\end{aligned}
$$

where $\varepsilon_{f}^{*} / \varepsilon_{f}$ is the ratio of multiaxial to uniaxial creep ductility and $n$ is the creep exponent in Eq. (5).

\section{Finite Element Implementation}

All finite element analyses in this study were conducted using the commercial code, ABAQUS 5.8 [25]. In what follows a small strain formulation is assumed so the effects of large geometry changes are ignored.

The creep strain, $\varepsilon^{c}$ (or $\varepsilon_{\omega}^{c}$ for a PST analysis) is calculated within an ABAQUS creep subroutine. The primary and secondary creep strain increments are calculated according to Eqs. (4) and (5):

$$
\begin{aligned}
& \Delta \varepsilon_{p}=C_{2}\left(C_{1} \sigma^{n_{1}}\right) \frac{1}{C_{2}} \varepsilon^{\frac{c_{2}-1}{c_{2}}} \Delta t \\
& \Delta \varepsilon_{s}=C \sigma^{n} \Delta t
\end{aligned}
$$

The creep strain increment, $\Delta \varepsilon^{\mathrm{c}}$, is then equal to the larger of the two increments obtained from Eq. (12),

$$
\Delta \varepsilon^{c}=\left\{\begin{array}{lll}
\Delta \varepsilon_{p} & \text { for } & \Delta \varepsilon_{p}>\Delta \varepsilon_{s} \\
\Delta \varepsilon_{s} & \text { for } & \Delta \varepsilon_{p} \leq \Delta \varepsilon_{s}
\end{array}\right.
$$


The damage parameter $\omega$ is also calculated within the subroutine according to Eq (7), where the integration is conducted numerically so that:

$$
\omega=\sum_{\Delta t} \frac{\Delta \varepsilon^{c}}{\varepsilon_{f}^{*}}
$$

where $\varepsilon_{f}^{*}$ is based on the current stress state and is evaluated from Eq. (10) or (11). When tertiary creep is included in the analysis, the creep strain rate and damage are coupled. The creep strain rate increment $\Delta \varepsilon_{\omega}^{\mathrm{c}}$ is then calculated from Eq. (8) as:

$$
\Delta \varepsilon_{\omega}^{c}=\frac{\Delta \varepsilon^{c}}{(1-\omega)^{m}}
$$

with $\Delta \varepsilon^{\mathrm{c}}$ given by Eq. (13). In order to avoid possible numerical problems with Eq. (15) as $\omega \rightarrow 1$, the maximum value of $\omega$ is limited to $\omega_{\max }=0.999$ in almost all analyses. In some cases $\omega_{\max }$ is taken to be 0.99 to examine the sensitivity of the results to the choice of $\omega_{\max }$.

In order to simulate crack growth due to damage processes the use of a nodal release approach is examined. In this case a node is released when the damage at adjacent integration points reaches $\omega_{\max }$. A user subroutine (subroutine MPC) is used to implement the nodal release procedure. Within this subroutine, the relative $y$ displacement of two connected nodes is held fixed until the damage condition is satisfied. Subsequent to the nodal release, the constraint in the $y$-direction is no longer applied and nodes can move freely. In this work it is assumed that crack growth will only apply along the symmetry plane, i.e. directly ahead of the notch. Therefore only these nodes are released in the analysis. Future work will examine the tendency for the crack to grow out of the plane by allowing nodal release along an arbitrary plane. Note that damage evolves throughout the specimen in the PST analyses, not just in elements directly ahead of the notch.

\subsubsection{Finite element mesh for notch geometry}

The geometry of the notched bars is shown in Fig. 1. As the material is isotropic and loading is along the $Z$-axis an axisymmetric analysis can be used to solve the problem. Taking advantage of the symmetry of the specimen only the shaded part of the specimen is modeled in the finite element analysis the finite element meshes to be used in the analysis are shown in Fig. 1(c). The figure shows only the portion of the mesh near the notch. It is well known that the use of a damage model incorporating material softening can lead to a mesh sensitive result, e.g. [26]. Therefore three different finite element meshes have been used in these analyses, with the smallest element in the mesh being $38 \mu \mathrm{m}, 25 \mu \mathrm{m}$ and $15 \mu \mathrm{m}$ for mesh 1, 2 and 3 in Fig. 1(c) respectively. In total approximately 490, 680 and 1390 linear axisymmetric elements are used for mesh 1, 2 and 3 respectively.

\section{Uniaxial response}

The PST material model, outlined in section 2 was used to fit the experimental creep data at $360^{\circ} \mathrm{C}$. In Fig. 2 the creep strain against time is shown for the PST model. The damage exponent $m$ for tertiary creep in Eq. (15) is fitted to the experimental data shown in the figure. It is seen that a single value of $m=2.4$ provides a reasonable fit 
to the experimental data. This value of $m$ has also been found to give a good prediction of the rupture time over a wide range of stresses, with rupture time for the material model corresponding to the time when $\omega=\omega_{\max }$.

\section{Notched bar results}

\subsection{Prediction of multiaxial ductility}

The multiaxial creep ductility models described in section 2.4 are first compared with experimental data. In Fig. 3 a comparison between the measured experimental creep failure strain and the predictions from Eqs. (10) and (11) is provided. Here data from a range of specimens with different notch acuity (and thus triaxiality) are presented. The failure strains for both uniaxial and notched tests ( $\varepsilon_{f}$ and $\varepsilon_{f}^{*}$ respectively) were obtained from the measured reduction of area in the specimen [15]. The stress triaxiality, $\sigma_{m} / \sigma_{e}$, for the experimental data was taken from the current code of practice for notched bar testing [27]. Table 3 provides the values of $\sigma_{m} / \sigma_{e}$ at the skeletal point for $n=16.8$ for the notch specimen in Fig. 1 obtained from the finite element analysis and the value from the code of practice [27] for comparison.

It may be seen in Fig. 3 that for $n=16.8$ both multiaxial models give similar predictions and are in reasonable agreement with the experimental data, though both are somewhat over-conservative at high values of triaxiality. It was found that by taking $n=2.0$ in the Cocks and Ashby model, Eq. (11), the predicted triaxiality dependence of the failure strain is closer to the mean of the experimental data. Note that the Rice and Tracey model is based on perfectly plastic material response and therefore has no dependence on creep exponent, $n$ (see Eq.(10)).

In what follows the Cocks and Ashby model with $n=16.8$ will be adopted for most of the FE analyses because it gives the more conservative results. For comparison, selected results will be presented for the Cocks and Ashby model with $n=2.0$.

\subsection{Prediction of creep rupture in notched bars}

In the notch bar analysis, the stress and strain fields are not uniform throughout the specimen. It is therefore necessary to consider the evolution of these fields as a function of position across the notch throat as well as time. Two rupture times have been defined to allow for this variation: a minimum rupture time, $t_{\text {rmin }}$, corresponding to the time at which the first element across the notch throat reaches $\omega=\omega_{\max }$ and a maximum rupture time, $t_{r m a x}$, when all the elements across the notch throat reach $\omega=\omega_{\max }$. The quantities, $t_{\text {rmin }}$ and $t_{\text {rmax }}$ may also be interpreted as the time for the initiation of damage and for final failure, respectively. The use of both of these rupture times is examined in the subsequent sections. Unless otherwise stated mesh 2 (see Fig. 1(c)) has been used in all these analyses.

\subsubsection{Analysis with PS and PST models}

Analyses were first carried out to examine the effect of plastic strain on the creep deformation and time to rupture in the notched bars. Both PS and PST creep models were examined. (Note that in a uniaxial analysis the plastic strain does not affect the creep response as no stress redistribution occurs under fixed load). In this section, for the PST analysis the damage variable is assumed to affect only the creep strain and the Young's modulus is unaffected.

Fig. 4 shows the axial deformation, over the $36 \mathrm{~mm}$ gauge length, and the rupture predictions obtained from the FE analysis. In Fig. 4(a) the axial displacements for the 
notch specimen of Fig. 1 at a net section stress, $\sigma_{\text {net }}=525 \mathrm{MPa}$, are plotted along with the experimental data (For this notch geometry, as shown in Table 3 the skeletal point stress triaxiality, $\left.\sigma_{m} / \sigma_{e} \approx 1.4\right)$. Also included in this figure is the value of damage initiation, $\mathrm{t}_{\mathrm{rmin}}$ (open circle), and maximum time, $\mathrm{t}_{\mathrm{rmax}}$ (open square), for each analysis. It may be seen in Fig. 4(a) that the primary creep region in all the analyses is relatively small and secondary/tertiary creep dominates the global deformation response. It may also be seen that for the PS creep analysis, plasticity affects only the initial axial deformation (i.e. strain on loading) and the overall secondary creep rate is almost unaffected. For the PST analysis, although there is only a small effect of plasticity in the secondary region, the tertiary region is somewhat extended when plastic strains are accounted for.

The values of $t_{\text {rmin }}$ and $t_{\text {rmax }}$ obtained from the finite element analysis are plotted directly in Fig. 4(b) as a function of the net section stress on a log-log plot. Note that for a uniaixal specimen, integration of Eqs. (5)-(8) leads to the result that the slope of the stress to time to rupture curve on a log-log plot is given by the creep exponent, $n$. The values of the slope of the finite element curves given in Fig. 4(b) and elsewhere in the paper range between 15.5 and 17.7, which is consistent with this observation ( $n$ for the material is 16.8). It is seen in Fig. 4(b) that $t_{\text {rmin }}$ provides a conservative prediction of the creep rupture time compared to the experimental data for all the models. In addition, $t_{r m i n}$ for the PST creep model gives more conservative predictions than that for the PS model while the inclusion of plasticity reduces the conservatism somewhat (i.e. rate of damage accumulation is decreased). The effect of plasticity is to limit the generation of very high stresses in the vicinity of the notch at short times. This leads to a reduction in the rate of damage accumulation in the early stage of creep and an increase in the value of $t_{\text {rmin }}$ (time to reach $\omega=\omega_{\max }$ ) though the effect on $t_{\mathrm{rmax}}$ is much weaker. The value of $t_{\mathrm{rmax}}$ obtained from the PS analysis is very unconservative (i.e. overpredicts the creep life by 2 orders of magnitude) and there is little difference in the value of $t_{\text {rmax }}$ obtained from an elastic and elastic-plastic analysis. Since the PS analysis does not take into account the tertiary strain and the resultant acceleration of creep deformation, it is not unexpected that a PS analysis provides a non-conservative prediction of the failure time. Note however that even in the PST analysis the rupture time (i.e. $t_{\operatorname{rmax}}$ ) is overestimated relative to the experimental data.

\subsubsection{Analysis incorporating elastic damage (PSTE model)}

In this section, the use of the PSTE model, where the elastic stiffness is affected by the damage through Eq. (9), is examined. Analyses with and without plastic strain are considered.

Fig. 5(a) shows the results for the axial deformation from the FE analysis using the PSTE model. It may be seen that in this case there is little difference between $t_{\text {rmin }}$ and $t_{r m a x}$ for both the elastic and elastic plastic analyses (compare Fig. 4(a)). In other words, the PSTE model predicts that once failure has initiated in the specimen creep rupture follows rapidly.

In Fig. 5 (b), the predicted values of $t_{\text {rmin }}$ and $t_{\text {rmax }}$ obtained from the PSTE model are shown. Also shown for comparison is the result for the elastic PST model. It is clear that, when the PSTE model is used, the predicted time to fracture imitation $\left(\mathrm{t}_{\mathrm{rmin}}\right)$ is considerably increased and the time to creep rupture $\left(t_{r \max }\right)$ is considerably reduced and both are much closer to the measured rupture time. 
The effect of incorporating elastic damage on the evolution of the hydrostatic stress across the notch throat is shown in Fig. 6. Here the hydrostatic stress at different distances from the notch root is plotted against time for both models. It can be seen in Fig. 6(a) that in the absence of elastic damage (PST model) after the hydrostatic stress reaches the peak value, it remains relatively high throughout the notch throat even at large values of $\omega$. However if elastic damage is included (PSTE model) the hydrostatic stress falls rapidly after it reaches the peak value and the peak translates with time from the vicinity of notch $(r / a=1)$ to the centre of notch $(r / a=0)$ in a smooth fashion.

Fig. 7 shows contours of creep damage at the notch throat obtained from the elastic PST and PSTE analyses. It can be seen that in addition to changing the predicted time to creep rupture, the PSET model also predicts a different pattern of damage. For the PST model (Fig. 7(a)) the peak damage grows in a direction inclined at an angle of about $45^{\circ}$ to the plane of the notch throat, while for the PSTE model (Fig. 7(b)) the damage remains close to the notch plane.

\subsection{Comparison of node-release model and fixed-mesh model}

In this section an additional feature is incorporated in the model - a node release method is implemented to represent the generation of a sharp crack due to creep damage. Here, a node is released and the traction along the element boundary reduced to zero, when damage reaches unity (in practice when $\omega=\omega_{\max }$ ) at adjacent integration points in the finite element model. In this section the results for the different material models in conjunction with this nodal release technique are examined. Plasticity effects are not included in these analyses.

Fig. 8 shows the results for the three material models. Although not plotted on the same scale, by comparing Fig. 4(a), Fig. 5(a) and Fig. 8(a) it may be seen that the use of the nodal release method has almost no effect on the results for the PSTE model, but has a very strong effect on the PST model. Note furthermore (compare Fig. 4(a) and Fig. 8(a)) that incorporation of the nodal release method leads to an improvement of the agreement of the PS model with the experimental data. This effect is seen more clearly in Fig. 8(b) where the values of $t_{\text {rmin }}$ and $t_{r m a x}$ are plotted against stress. The effect of incorporating the nodal release technique is in all cases to reduce the difference between $t_{\text {rmin }}$ and $t_{r \operatorname{rmax}}$, i.e. once a crack has initiated damage progresses rapidly to final failure. This is due to that fact that following the release of a node, the stress at the newly created crack tip is amplified and the value of damage at the crack tip increases rapidly even for the PS model with uncoupled creep damage. As a result, the damage propagates rapidly leading to final creep rupture. All three models now give conservative predictions using either $t_{\text {rmin }}$ or $t_{\text {rmax }}$, with the PSTE model remaining closest to the experimental data and the PST model giving the most conservative prediction.

\section{Sensitivity analysis}

In this section the sensitivity of the finite element predictions to a number of key problems parameters is examined. These are the uniaxial creep failure strain, $\varepsilon_{\mathrm{f}}$, which appears in Eqs. (10) and (11); the multiaxial creep model used; value of $\omega_{\max }$ used in the model and the finite element mesh size. 


\subsection{Effect of uniaxial creep failure strain}

The model chosen for this sensitivity study is the PSTE model without plastic strain and without nodal release, which provides very close agreement to the experimental data. Two different uniaxial creep failure strains are used- $\varepsilon_{\mathrm{f}}=0.18$ (the mean experimental value, which has been used in the analyses to date) and $\varepsilon_{\mathrm{f}}=0.5$, which was the maximum failure strain observed in the uniaxial creep tests. Fig. 9 shows the sensitivity of the predicted creep deformation and rupture time to the value of $\varepsilon_{f}$. Note that because of the non-linear nature of the damage law, Eq. (8), this effect cannot be predicted a priori. It can be seen that there is a significant effect on the predicted response-a threefold increase in $\varepsilon_{f}$ leads to almost an eight fold increase in $t_{\text {rmin }}$ and a ten fold increase in $t_{\text {rmax }}$ (see Fig. 9(a)). This result holds for all stress levels as seen in Fig. 9(b). Note that when $\varepsilon_{f}=0.5$ the value of $\mathrm{t}_{\mathrm{rmax}}$ is considerably greater than $\mathrm{t}_{\mathrm{rmin}}$ unlike the result for $\varepsilon_{f}=0.18$.

\subsection{Effect of multiaxiality model}

Fig. 10 shows the effect of the choice of creep multiaxiality model on the predictions, again using the PSTE model. Here the Cocks and Ashby model, Eq. (11) was used with $n=16.8$ (corresponding to the secondary creep properties of the material) and $n=2.0$ (the value which gave a prediction close to the mean of the experimental data (see Fig. 3)). These models will be referred to as the CA16 and CA2 models respectively throughout this section. It may be seen in Fig. 10(a) that the CA2 model provides poor agreement with the experimental data, compared to the CA16 model. Furthermore, Fig. 10(b) shows that the CA2 model does not provide a good prediction of the creep rupture times being generally non-conservative (based on both $t_{r m i n}$ and $\left.t_{r \max }\right)$ - use of the CA2 model leads to a predicted increase in the lifetime of about a factor of 5 (based on $t_{\text {rmax }}$ ) over that CA16 model. This result is somewhat surprising in view of the fact that the CA2 model appears to give an improved prediction of the multiaxial failure strain (see Fig. 3). However, it should be pointed out that the data in Fig. 10 are for a single notch acuity (i.e. a single notch triaxiality, $\sigma_{\mathrm{m}} / \sigma_{\mathrm{e}} \approx 1.4$ ) while the data in Fig. 3 are for a range of triaxialities. Indeed the CA2 model is seen to be somewhat non-conservative for two of the three data points at $\sigma_{\mathrm{m}} / \sigma_{\mathrm{e}} \approx 1.4$ in Fig. 3 .

\subsection{Effect of $\omega_{\max }$}

Fig. 11 shows the sensitivity of the results to the value of $\omega_{\max }$ used to release a node in the nodal release model in conjunction with the PSTE model. It may be seen that decreasing $\omega_{\max }$ from 0.999 to 0.99 has a large effect on the predictions in the tertiary regime (Fig. 11 (a)) and on the values of $t_{r \min }$ and $t_{\text {rmax }}$ (Fig. 11 (b) and (c)). For example as seen in Fig. 11(c) a $1 \%$ change in the value chosen for $\omega_{\max }$ leads to a doubling in the in the value of $\mathrm{t}_{\mathrm{rmax}}$. These results suggest that care should be taken in the choice of the value of $\omega_{\max }$ and it should not simply be taken as some arbitrary value close to unity. Note that in a uniaxial analysis there is almost no difference in the rupture time predicted from $\omega_{\max }=0.99$ and 0.999 so a uniaxial analysis could not be used as a guide to the appropriate value to choose for $\omega_{\max }$. This strong effect is seen in the notched bars because, due to stress redistribution during creep, the rate of increase of damage at a material point is reduced, compared to a uniaxial analysis. Therefore a small increase in $\omega_{\max }$ will result in a larger increase in $t_{r m i n}$ and $t_{r \max }$ than that seen in a uniaxial analysis. 


\subsection{Effect of mesh size}

Fig. 12 shows the effect of mesh size on the result for the models examined here. Fig. 12(a) gives the result for the PST model-little mesh size effect is evident in the load line displacement against time prediction (see also Table 4). It is to be expected that in the absence of damage, the three meshes will give very similar results (this has been confirmed from a PS analysis on all three meshes). However, it is surprising that the incorporation of creep damage does not lead to significant mesh dependence. The largest effect is seen in $t_{\text {rmin }}$, the finest mesh having a $23 \%$ reduction in $t_{\text {rmin }}$ compared to the coarsest mesh (see Table 4). Fig. 12(b)-Fig. 12(e) show the mesh size effect for the PS model, the PST node-release model, the PSTE model and the PSTE noderelease model. In all cases it may be seen (see also Table 4) that both $t_{\text {rmin }}$ are $t_{\text {rmax }}$ are strongly affected by mesh size, with the finest mesh giving the lowest values for $t_{\text {rmin }}$ are $t_{\text {rmax }}$. Fig. 12(f) shows the mesh size effect for the PSTE model in conjunction with the CA2 multiaxiality model. In this case a different trend is seen to the other analyses as the finest mesh, mesh 3 , has a lower creep rate at large times and a larger predicted rupture time. This effect is believed to be linked to the predicted damage evolution in the specimens. Contours of damage are plotted in Fig. 13 for the three analyses. It is seen that the direction of damage propagation is different for each mesh. For mesh 1, (Fig. 13(a)) the peak damage occurs directly ahead of the notch root. However, for mesh 2 (Fig. 13(b)) the contour of peak damage is inclined at an angle of around $30^{\circ}$ to the plane of the notch throat. For mesh 3 (Fig. 13(c)) the peak damage contour is at an angle of around $45^{\circ}$ to the plane of the notch throat. (Note that these specimens are almost symmetric about the notch centre-line (see Fig. 1) and the asymmetry of the result seen in Fig. 13 (b) and (c) is unexpected. The result is believed to be due to slight asymmetry in the mesh design leading to a preferred path for damage propagation.) These different directions of damage propagation are expected to affect the value of $t_{\text {rmax }}$ for each mesh. Experimental observations generally support the predictions shown in Fig. 13(a), with damage and crack initiation extending at the net section, normal to the loading direction.

Clearly all the models except the PST model show strong sensitivity to mesh size. Therefore when making comparison between these models and experimental data an appropriate mesh size must be chosen. Note also that in a uniaxial analysis the mesh size will have no effect on the result (as the deformation is homogeneous within the finite element analysis). Thus data from uniaxial tests cannot be used to provide information on the appropriate mesh size to be used in the modelling of the notch tests. It may be appropriate to base the mesh size on some physical material length scale, e.g. appropriate void spacing in void growth model, or on some geometrical feature, e.g. notch radius. Further work is required to develop an optimum mesh size for the material under examination here.

\section{Conclusions}

In this paper, a multiaxial damage model linked to the creep strain rate and stress triaxiality has been adopted to predict creep displacements and rupture life under multiaxial stress conditions. Three material models have been used in the creep regime, a primary-secondary (PS) creep model a primary-secondary-tertiary (PST) model and a primary-secondary-tertiary model including an elastic damage term (PSTE). The effect on the predictions of incorporating rate independent plastic strains has also been examined. Finally, the use of a nodal release method to model the effect 
of creep crack growth has been studied. Based on finite element calculations of notched specimens for a range of stresses, it was found that

(1) The PST creep analysis provides more conservative predictions than a PS analysis and the difference between the initiation of creep damage, $t_{\text {rmin }}$, and final failure, $t_{\text {rmax }}$, for the PST creep model is much smaller than those for the PS creep model.

(2) Incorporation of plasticity leads to a less conservative prediction for the time to fracture initiation, $t_{\mathrm{rmin}}$, by reducing the magnitude of stress in the specimen at short time.

(3) The PSTE analysis predicts that the values of $t_{r m i n}$ and $t_{r m a x}$ converge, as damage spreads rapidly through the specimen after first initiation, and the prediction of failure times becomes less conservative.

(4) The use of a nodal release crack growth model has little effect on the predictions of the PSTE model but reduces the value of $t_{\text {rmax }}$ for the other models.

(5) The sensitivity of the results to the value chosen for the creep failure strain and the creep triaxiality model was examined and it was found that these two factors strongly affect the predicted rupture time.

(6) It was found that the PSTE model with nodal release is quite sensitive to the value of maximum damage, $\omega_{\max }$.

(7) The effect of mesh size on the finite element predictions was examined. All models except the PS and PST model were shown to be strongly mesh dependent, with the predicted creep rupture life and damage propagation pattern being dependent on the choice of mesh.

\section{Acknowledgements}

The authors are grateful to Dr Adam Bettinson and Dr Farid Biglari for their assistance in the implementation of the nodal release technique and the finite element modelling. Helpful discussions with Prof. George Webster of Imperial College and Prof. Alan Cocks of Leicester University are also acknowledged. Thanks is also due to the partners of the EC funded FP4 collaborative programme ' $\mathrm{CCG}$ in $\mathrm{C}-\mathrm{Mn}$ at 320$400{ }^{\circ} \mathrm{C}^{\prime}$ for the use of their test data.

\section{References}

[1] Webster G.A. and Ainsworth R.A. (1993). High Temperature components life assessment. Chapman \& Hall

[2] Al-Faddagh K.D., Fenner R.T. and Webster G.A. (1982). Steady-state stress distributions in circumferentially notched bars subjected to creep. J. Strain Analysis, 17, 123-132.

[3] Kwon, O., Nikbin, K. and Webster, G.A. Failure mechanism in carbon manganese steel at $360^{\circ} \mathrm{C}$ under multi-axial stress states' CREEP 7, Conf. Tsukuba, Japan, June 2001.

[4] Hayhurst D.R. and Webster G.A. (1986). An overview on studies of stress state effects during creep of circumferentially notched bars, in: Gooch, D.J., How, I.M., editors. Techniques for multiaxial creep testing, Amsterdam: Elsevier, 137-143

[5] Webster G.A., Aplin P.F., Cane B.J., Dyson B.F., and Loveday M.S. (1992). A code of practice for notched bar creep rupture testing: procedures and interpretation of data for design, in Harmonisation of testing practice for high 
temperature materials. Eds M.S. Loveday and T.B. Gibbons, Elsevier Applied Science, London, 295-330.

[6] Kachanov L.M. (1986). Introduction to Continuum Damage Mechanics. Kluwer Academic Publishers, Dordrecht

[7] Rabotnov Y.N. (1969) Creep Problems in Structual Members. F.A.Leckie (ed.), North Holland, Amsterdam

[8] Hyde T.H., Xia, L. and Becker A.A. (1996). Prediction of Creep Failure Aeroengine Materials under Multi-axial Stress States. Int. J. Mech. Sci., 38, 4, 385-403

[9] Harlow D.G. and Delph T.J. (1995). A computational probabilistic model for creep-damaging solids. Comp. \& Struc. 54, 161-166

[10] Bodnar A., Chrzanowski M. and Nowak K. (1996). Brittle failure lines in creeping plates. Int. J. Press. Ves. \& Piping. 66, 253-261

[11] Bettinson A.D. (2001). The Influence of Constraint on the Creep Crack Growth of $316 \mathrm{H}$ Stainless Steel. Ph.D thesis Imperial College London, UK.

[12] Hayhurst D.R., Dimmer P.R. and Morrison C.J. (1984). Development of continuum damage in the creep rupture of notched bars. Phil. Trans. R. Soc. London, A311, 103-129

[13] Perrin I.J. and Hayhurst D.R. (1999). Continuum damage mechanics analysis of type IV creep failure in ferritic steel crossweld specimens. Int. J. Press. Vess. and Piping. 76, 599-617

[14] Bhattacharya B. and Ellingwood B. (1999). A new CDM-based approach to structural deterioration. Int. J. Sol. \& Struc. 36, 1757-1779

[15] Kwon O. (1998). Failure and Fracture at Low Creep Temperature. Ph.D thesis Imperial college

[16] Webster G. A. (1966). A widely applicable dislocation model for creep. Phil. Mag., 14, 775-783

[17] RCC-MR (1985). Design and Construction rules for Mechanical Components of FBR Nuclear Islands. AFCEN, Paris

[18] Norton F.H. (1929). The Creep of Steel at High Temperatures. McGraw-Hill, London.

[19] Bassani, J.L. and Hawk, D.E. (1990). Influence of damage on crack-tip fields under small scale creep, Int. J. Fract., 42 157-172.

[20] Rice J.R. and Tracey D.M. (1969). On the Ductile Enlargement of Voids in Triaxial Stress Fields. J. Mech. Phys. Solids, 17, 201-217.

[21] Cocks A.C.F. and Ashby M.F. (1980). Intergranular Fracture in Power Law Creep under Multiaxial Stress. Metal Science, 14, 395-402.

[22] McClintock F.A. (1968). A Criterion for Ductile Fracture by the Growth of Holes. J. App. Mech., 35, 363-371.

[23] Budiansky B., Hutchinson J.W. and Slutsly S. (1982). Void Growth and Collapse in Viscous Solids, Mechanics of Solids, H.G. Hokins and M.J. Sewell (eds.), Pergamon Press, Oxford.

[24] Spindler, M.W. (1994). The Multiaxial Creep of Austenitic Stainless Steels. Nuclear Electric Report TIGM/REP/0014/94.

[25] ABAQUS manual version 5.8, 1998. Hibbitt, Karlsson \& Sorensen, Inc. 
[26] Murakami S., Liu.Y. and Mizuno M. (2000). Computational methods for creep fracture analysis by damage mechanics. Comput. Methods Appl. Mech. Engrg., 183, 15-33

[27] Webster G.A. and Nikbin K.M., Re-analysis of Notched Bar Skeletal Point Stresses using Finite Element Methods. Report ME 276/01, Imperial College, 2001. 
Table 1 Elastic-plastic material properties of C-Mn steel at $360^{\circ} \mathrm{C}$

\begin{tabular}{|c|c|c|c|}
\hline $\mathrm{E}$ & $v$ & $\sigma_{0.2}$ & $\sigma_{\text {UTS }}$ \\
\hline $190 \mathrm{GPa}$ & 0.3 & $240 \mathrm{MPa}$ & $570 \mathrm{MPa}$ \\
\hline
\end{tabular}

Table 2 Constants for primary and secondary creep model for C-Mn steel (time in h, stress in $\mathrm{MPa}$ )

\begin{tabular}{|c|c|c|c|c|c|}
\hline Temperature & $C_{1}$ & $C_{1}$ & $n_{1}$ & $C$ & $n$ \\
\hline $360^{\circ} \mathrm{C}$ & $3.84 \times 10^{-18}$ & 0.367 & 5.64 & $1.37 \times 10^{-49}$ & 16.8 \\
\hline
\end{tabular}

Table 3 Skeletal stress ratio for creep exponent $n=2.0$ and 16.8

\begin{tabular}{|c|c|c|}
\hline & $n=16.8$ & Handbook [26] \\
\hline$\sigma_{m} / \sigma_{e}$ & 1.44 & 1.43 \\
\hline
\end{tabular}

Table 4 Comparison of $t_{\text {rmin }}$ and $t_{\text {rmax }}$ between mesh 1 and mesh 3

\begin{tabular}{|c|c|c|c|c|c|c|}
\hline & PST $^{\dagger}$ & PS_NR & PST_NR & PSTE & PSTE_NR & PSTE_CA2 \\
\hline $\mathrm{t}_{\mathrm{rmin}(\mathrm{i})} / \mathrm{t}_{\mathrm{rmin}(\mathrm{iii})}$ & 1.23 & 1.22 & 1.23 & 1.48 & 1.50 & 1.56 \\
\hline $\mathrm{t}_{\mathrm{rmax}(\mathrm{i})} / \mathrm{t}_{\mathrm{rmax}(\mathrm{iii})}$ & 1.07 & 1.87 & 1.30 & 1.42 & 1.46 & 0.96 \\
\hline
\end{tabular}

${ }^{\dagger}$ PST $\equiv$ primary-secondary-tertiary creep model

PSTE $\equiv$ primary-secondary-tertiary creep model with elastic damage.

- NR $\equiv$ node-release model

- $\mathrm{CA} 2 \equiv n=2.0$ in Cocks and Ashby model 


\section{Appendix, Effect of stress triaxiality on failure strain using the Rice and Tracey relation}

In [A1], Rice and Tracey provide an expression for void growth over the full range of triaxialities:

$$
\frac{\dot{r}}{r \dot{\varepsilon}}=0.558 \sinh \left(\frac{3 \sigma_{\mathrm{m}}}{2 \sigma_{\mathrm{e}}}\right)+0.008 \cosh \left(\frac{3 \sigma_{\mathrm{m}}}{2 \sigma_{\mathrm{e}}}\right) .
$$

The second term in this equation is typically at least an order of magnitude smaller than the first term and can be neglected, so that the void growth rate may be written to a good approximation as,

$$
\frac{\dot{r}}{r \dot{\varepsilon}}=0.558 \sinh \left(\frac{3 \sigma_{\mathrm{m}}}{2 \sigma_{\mathrm{e}}}\right) .
$$

Integrating Eq. A2 from an initial void size, $r_{i}$ to a final void size, $r_{f}$, with constant triaxiality, gives the failure strain, $\varepsilon_{\mathrm{f}}^{*}$ as,

$$
\varepsilon_{\mathrm{f}}^{*}=1.792 \ln \left(r_{f} / r_{i}\right) / \sinh \left(\frac{3 \sigma_{\mathrm{m}}}{2 \sigma_{\mathrm{e}}}\right) .
$$

Assuming that the initial and final void sizes are independent of triaxiality, we can normalise the failure strain, $\varepsilon_{\mathrm{f}}^{*}$, in Eq. A3 by the uniaxial failure strain, $\varepsilon_{\mathrm{f}}$, given by setting $\sigma_{\mathrm{m}} / \sigma_{\mathrm{e}}=0.33$ in Eq. A3 to get,

$$
\frac{\varepsilon_{\mathrm{f}}^{*}}{\varepsilon_{\mathrm{f}}}=0.521 / \sinh \left(\frac{3 \sigma_{\mathrm{m}}}{2 \sigma_{\mathrm{e}}}\right) \text {. }
$$

Note that alternative expressions for multiaxial failure strain based on the Rice and Tracey void growth model are given in e.g. [A2], [A3]. However, these expressions are based on the high triaxiality approximation to Eq. A1, which should not be used to determine the void growth under uniaxial conditions. It has been shown in [A4] that the use of the high triaxiality model of [A2] and [A3] can lead to multiaxial ductilities up to $60 \%$ greater than those predicted by Eq. (A4).

\section{References}

[A1] Rice J.R. and Tracey D.M. (1969). On the Ductile Enlargement of Voids in Triaxial Stress Fields. Jnl. of Mech. Phys. Solids, 17, 201-217.

[A2] Penny R.K. and Marriot D.L., "Design for Creep", Chapman and Hall, London, 1995.

[A3] Webster G.A. and Ainsworth R.A. (1993). High Temperature components life assessment. Chapman \& Hall

[A4] Bettinson A.D. (2001). The Influence of Constraint on the Creep Crack Growth of $316 \mathrm{H}$ Stainless Steel. Ph.D thesis Imperial College London, UK. 
(a)

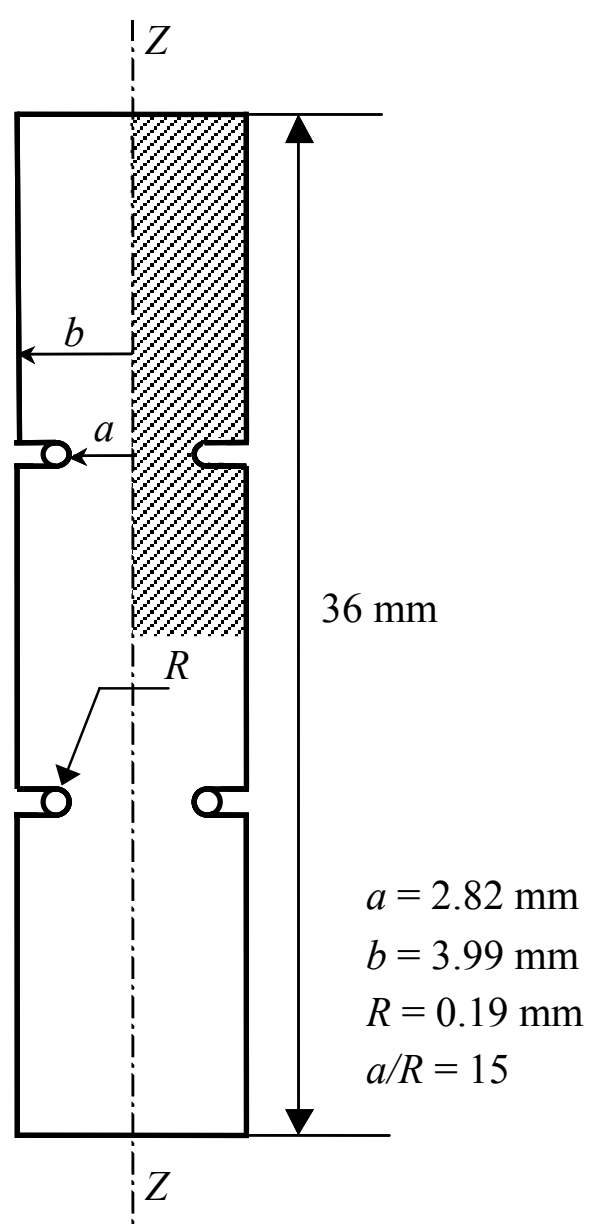

(b)

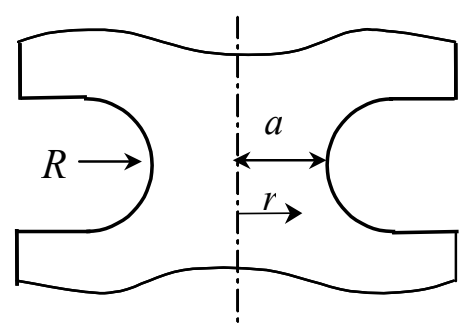

(c)

mesh 1

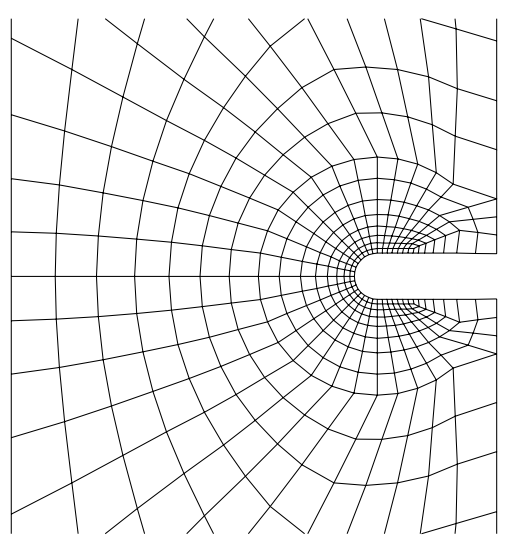

mesh 2
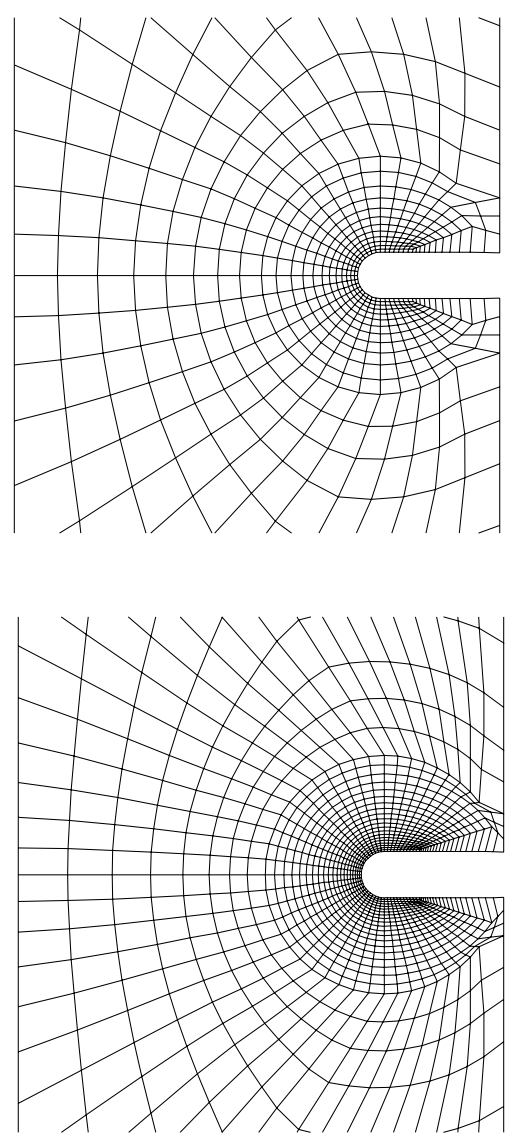

Fig. 1 Schematic of notched bar specimen (a) whole specimen, (b) details of notch throat and (c) three finite meshes used in the analysis 


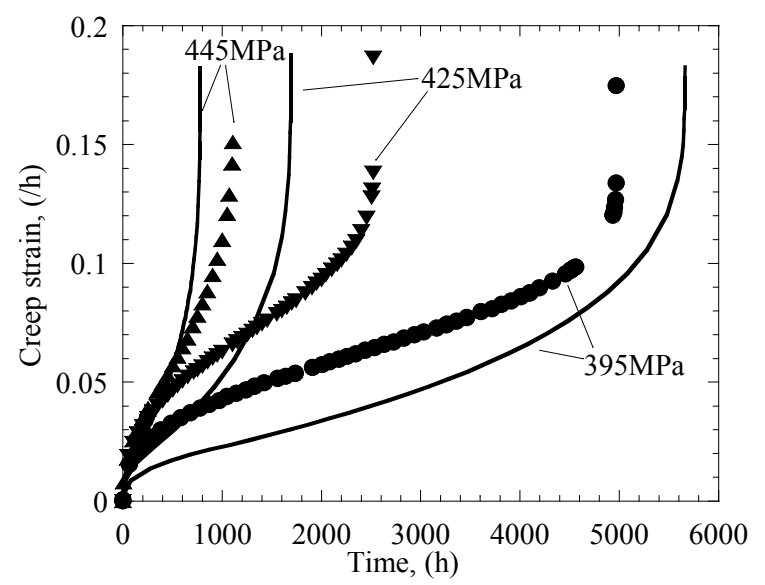

Fig. 2 Comparison of experimental data (symbols) and predicted PST curves (solid) for $\mathrm{C}-\mathrm{Mn}$ steel at $360^{\circ} \mathrm{C}$ at different stress levels

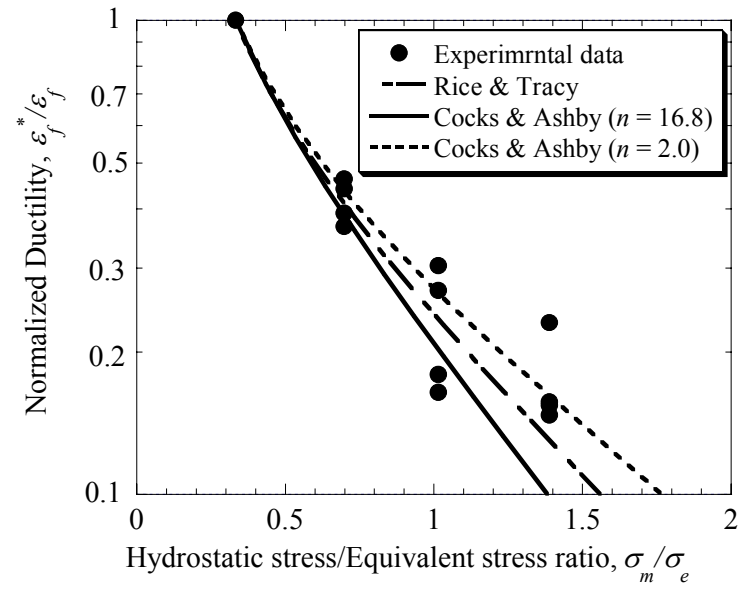

Fig. 3 Comparison of the experimental creep failure strain with analytical multiaxial creep ductility models

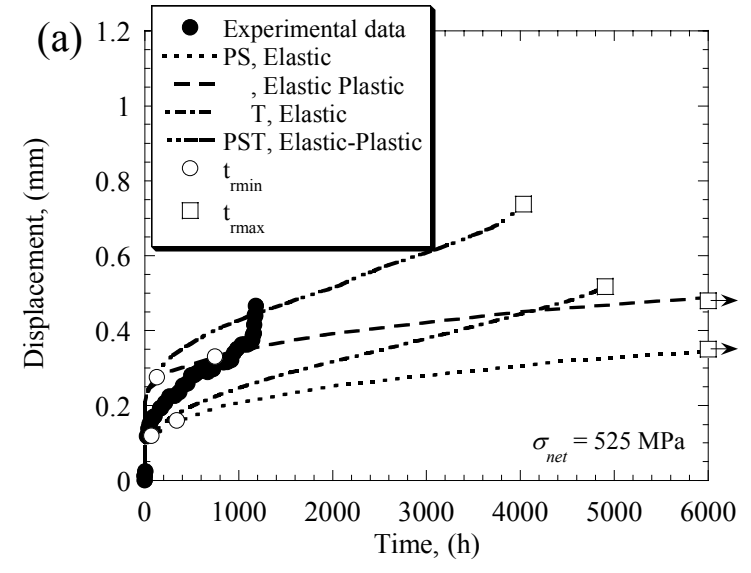

(b)

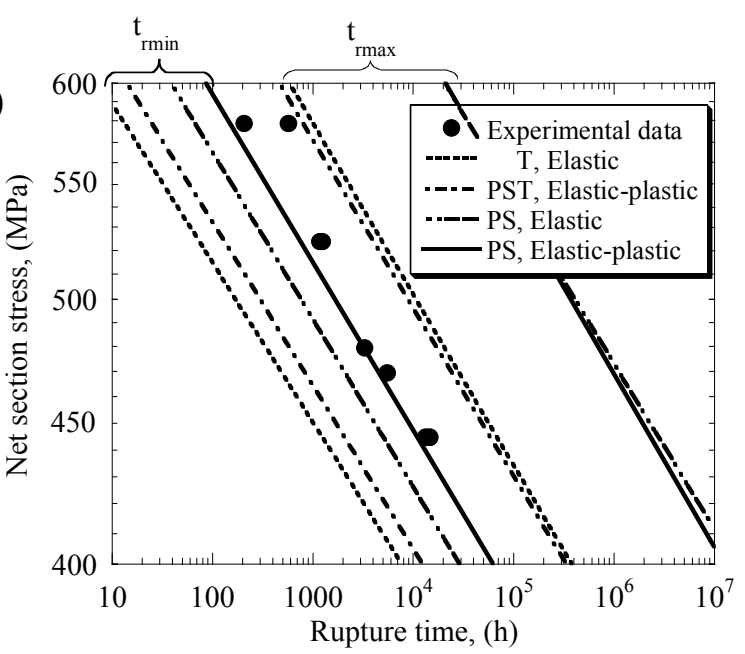

Fig. 4 (a) Axial displacements for $\sigma_{\text {net }}=525 \mathrm{MPa}$ and (b) rupture predictions for PS and PST creep analyses with and without plastic deformation. 

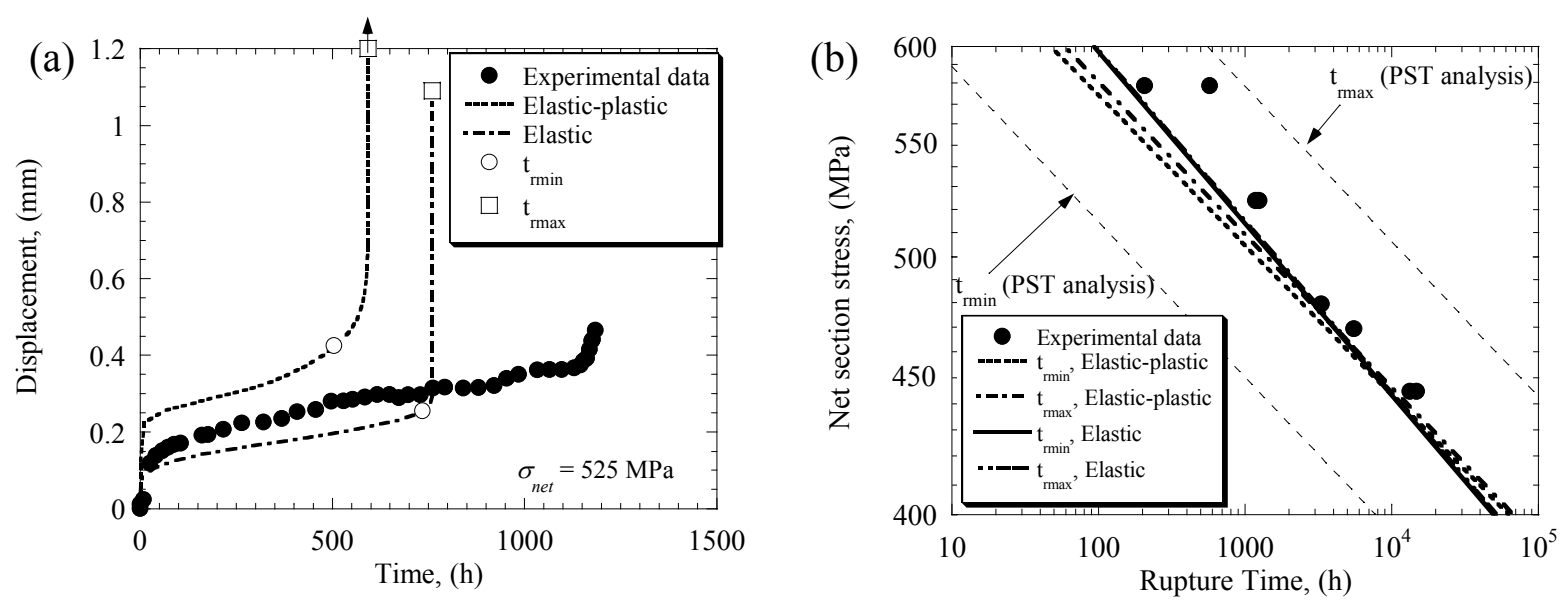

Fig. 5 (a) Axial displacement and (b) rupture prediction for elastic and elastic-plastic PSTE analysis
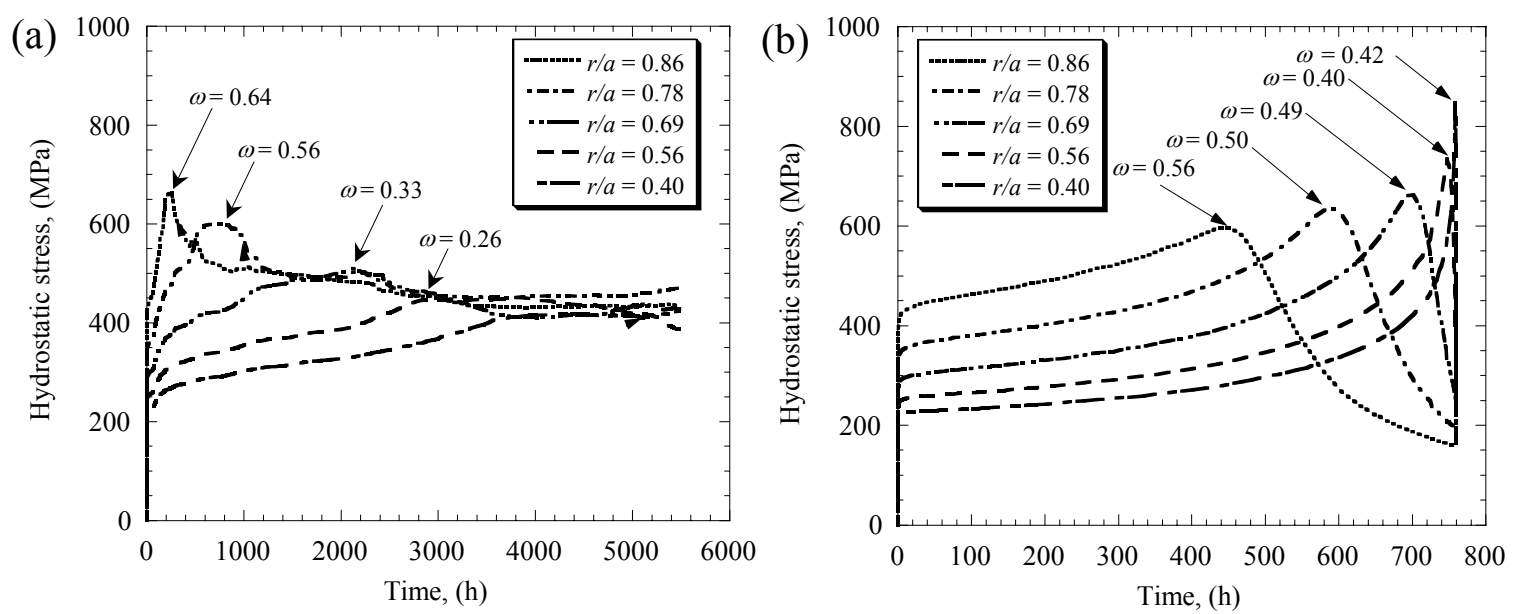

Fig. 6 Hydrostatic stresses against time for (a) elastic PST analysis (b) elastic PSTE analysis 


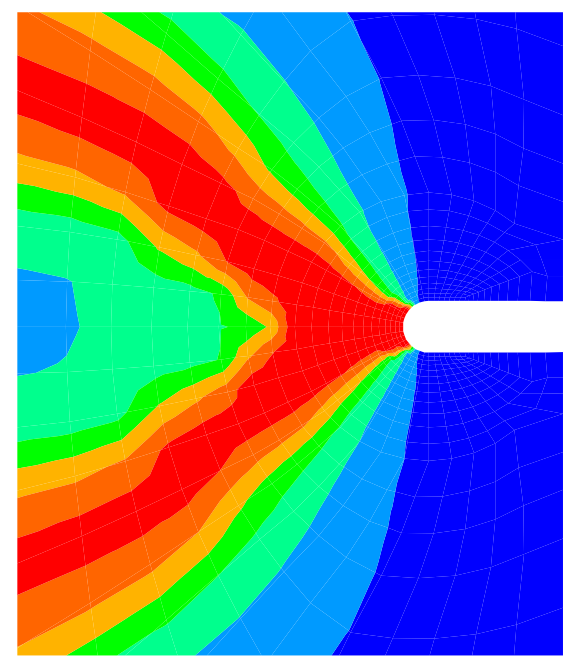

(a)

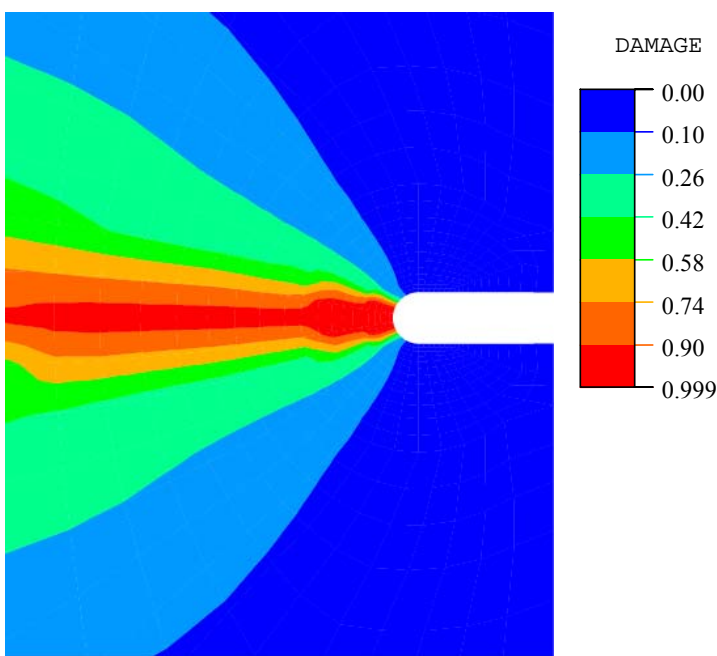

(b)

Fig. 7 Contour plot of damage at notch throat for (a) elastic PST analysis (b) elastic PSTE analysis
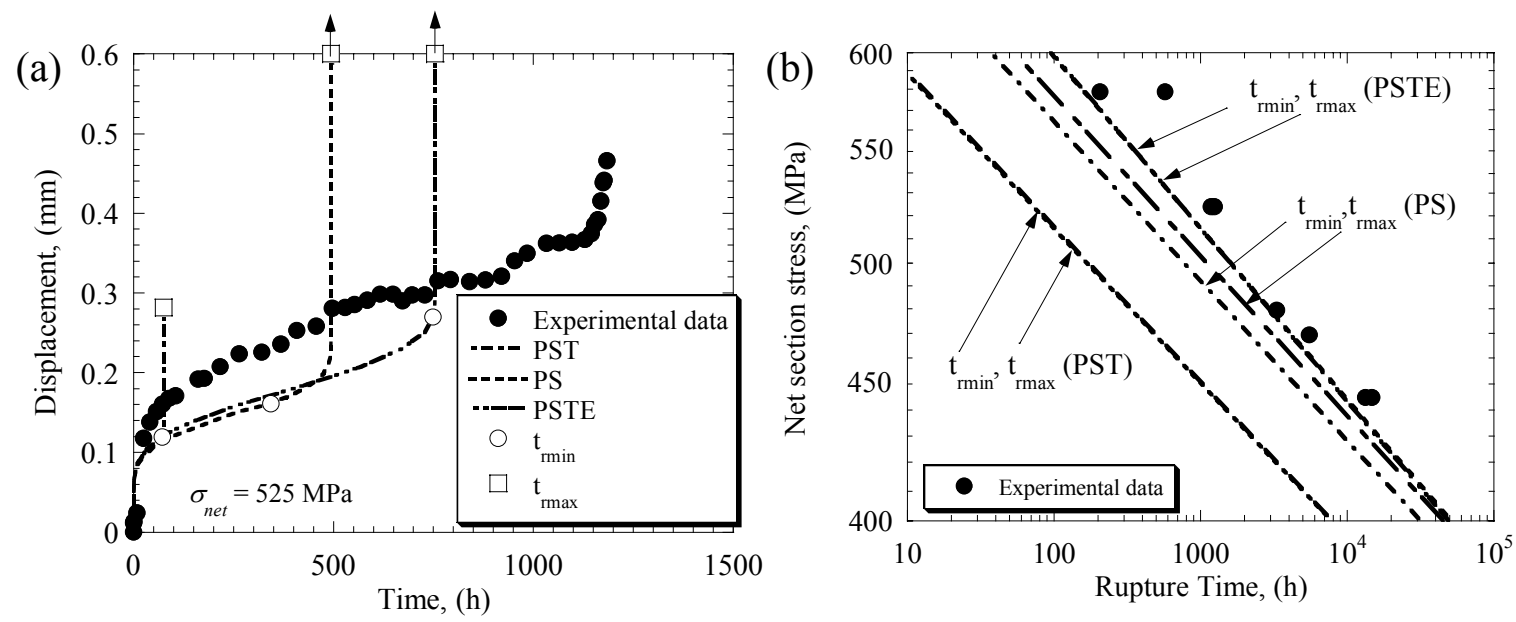

Fig. 8 (a) axial displacement and (b) rupture prediction using node-release model 

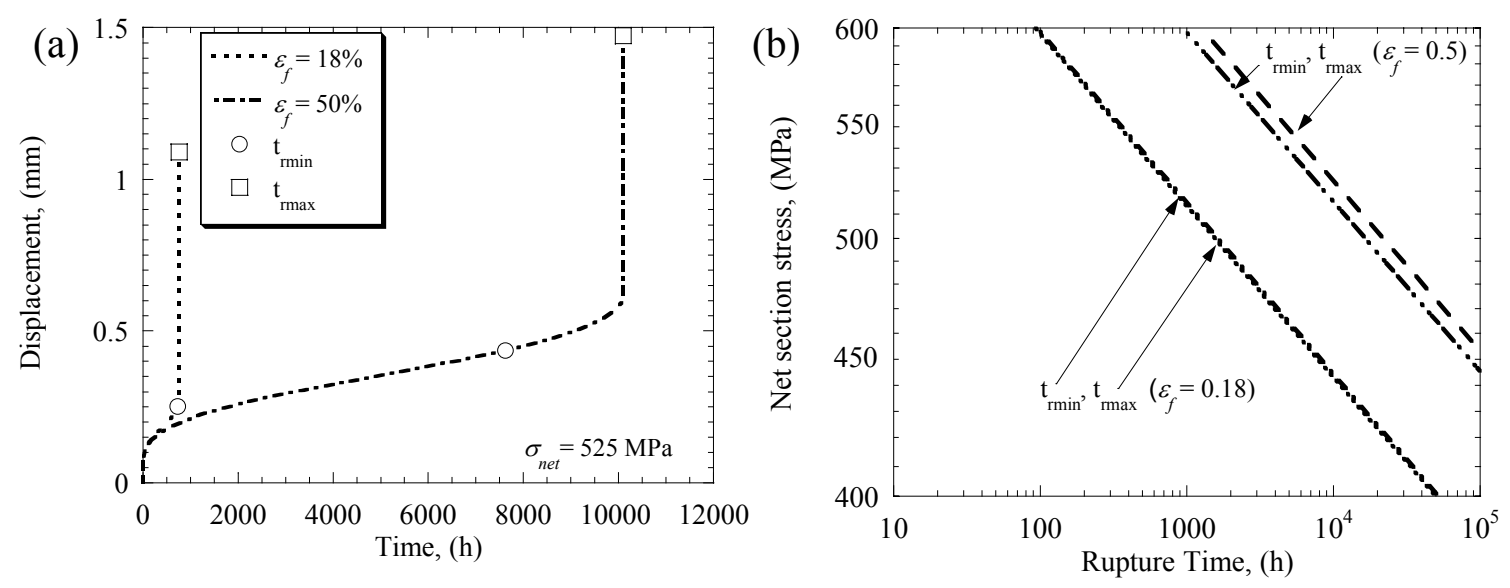

Fig. 9 Sensitivity of prediction to the creep failure strain (a) axial displacement and (b) rupture prediction
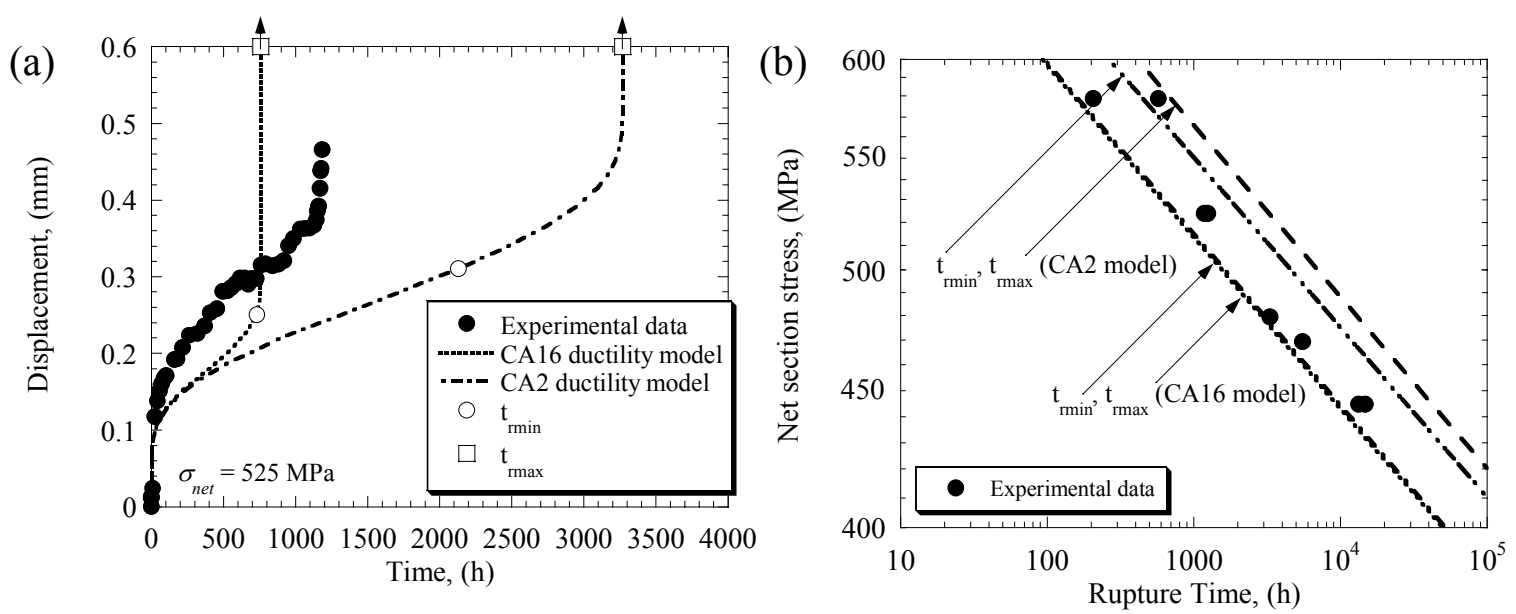

Fig. 10 Sensitivity of state of stress effect (a) axial displacement and (b) rupture prediction
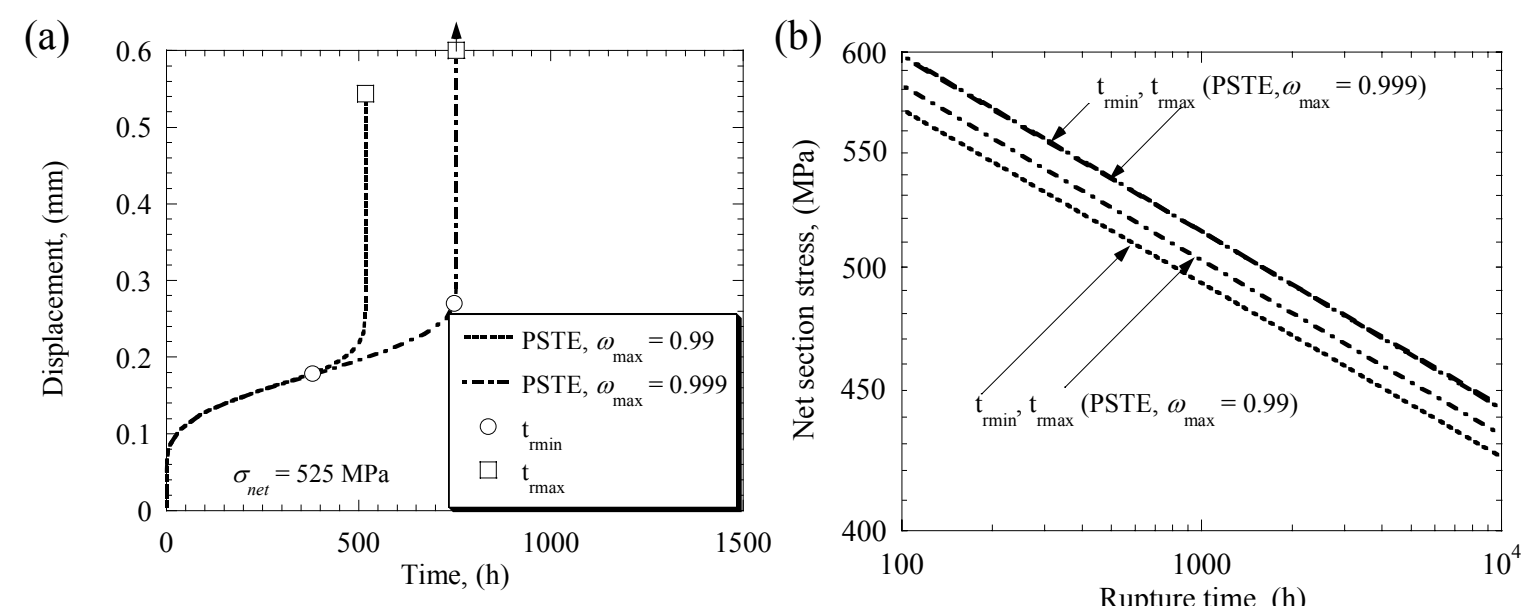

Fig. 11 Sensitivity of result to $\omega_{\max }$ in crack growth model (a) axial displacement (b) rupture prediction 

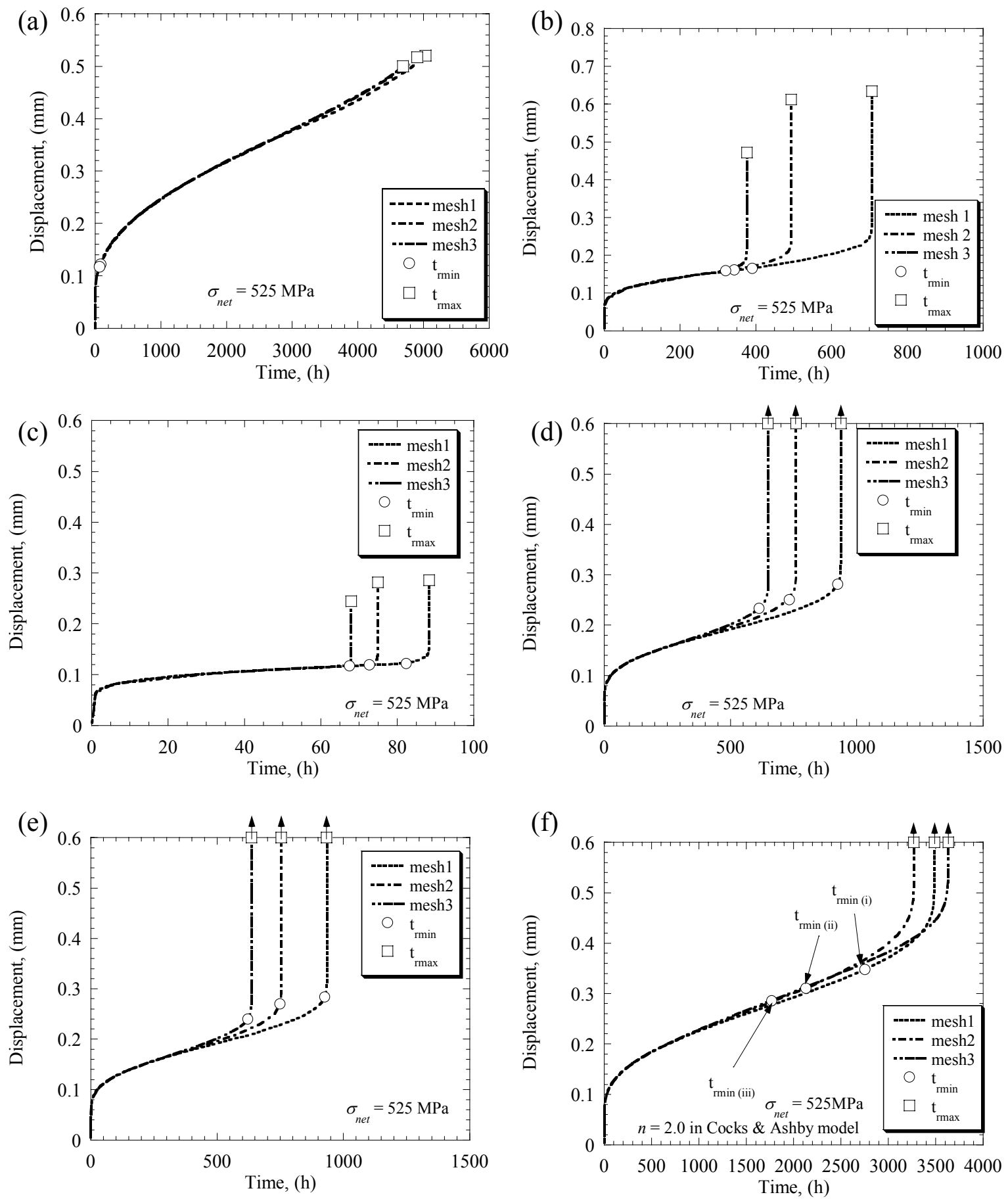

Fig. 12 Mesh size effect (a) PST creep model (b) PS model with nodal release (c) PST model with nodal release (d) PSTE model (e) PSTE model with nodal release (f) PSTE model using CA2 creep ductility model 


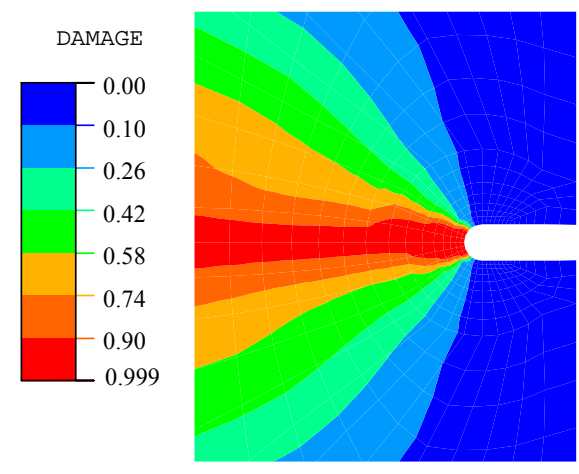

(a)

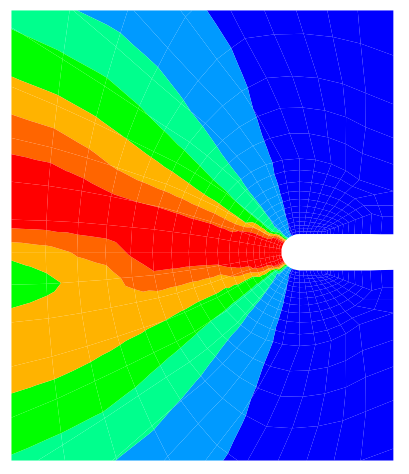

(b)

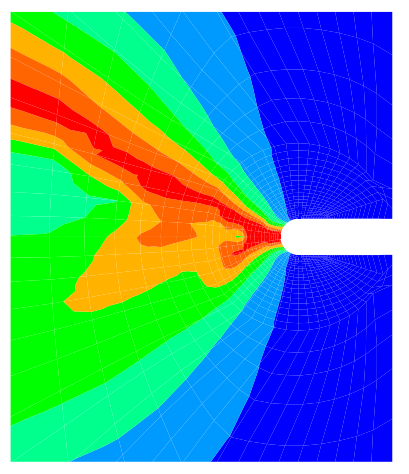

(c)

Fig. 13 Contour plot of damage at notch throat obtained from PSTE analysis with CA2 creep ductility model (a) mesh1 (b) mesh2 (c) mesh3 